\title{
Entre o real e o ideal: A literatura infantil na Educação Infantil
}

\section{Laiana Rosendo Oliveira*}

Graduação em Letras - Universidade Federal da Paraíba (2017). Mestrado em Letras pela Universidade Federal de Campina Grande (2020).

iD https://orcid.org/0000-0003-4466-8953

\section{José Helder Pinheiro Alves ${ }^{* *}$}

Graduação em Letras - Faculdades Integradas de Uberaba (1983), Mestrado em Letras (Literatura brasileira) pela Universidade de São Paulo (1992), Doutorado em Letras (Literatura brasileira) pela Universidade de São Paulo (2000) e Pós-doutorado pela Universidade Federal de Minas Gerais (2004). Professor Titular em Literatura Brasileira na Universidade Federal de Campina Grande, PB. É membro do GT Literatura e ensino da ANPOLL.

(iD) https://orcid.org/0000-0003-4304-7178

Recebido: 26 mai. 2020. Aprovado: 19 set. 2020.

\section{Como citar esta resenha:}

OLIVEIRA, Laiana Rosendo; ALVES, José Hélder Pinheiro. Entre o real e o ideal: a literatura infantil na Educação Infantil. Revista Letras Raras. Campina Grande, v. 9, n. 4, p. 287-298, dez. 2020.

GIROTTO, C. G. G. S.; SOUZA, R. J. de (orgs.). Literatura e educação infantil. Campinas: Mercado de Letras, 2016. (Livros, Imagens e Prática de Leitura, v. 1. 226 p. Para ler, Contar e Encantar, v. 2. 223 p. Série Literatura, Leitura e Educação Infantil).

\section{Introdução}

A Educação Infantil foi idealizada como espaço preparatório para o Ensino Fundamental por muito tempo e a literatura infantil, assumiu uma posição também herdada pelo ensino e imposição A história de ambas é marcada pelo ensino técnico, utilitário e dependente de outros segmentos. A obra a seguir desmistifica tais percepções e oportuniza a figura mediador, valoriza

\laianarosendo@gmail.com

**

helder.pinalves@gmail.com 


\section{Penista Leteas Parar \\ ISSN: 2317-2347 - v. 9, n. 4 (2020) \\ Todo o conteúdo da RLR está licenciado sob Creative Commons Atribuição 4.0 Internacional}

o educador nesse processo de vivência literária, como também, protagoniza a criança, como autônoma no processo multifacetado da literatura em sua formação. Nessa perspectiva, ela pode ser considerada uma representação da mudança que ainda está em transição e se fortalece com reflexões tão profundas como essas.

Os estudos sobre a literatura infantil brasileira podem ser agrupados em, pelo menos, duas perspectivas: as obras historiográficas e as obras voltadas para a literatura infantil no âmbito escolar. O primeiro grupo é composto por autores como Arroyo (1963), importante precursor, seguido por Coelho (1984), Zilberman e Lajolo (1985) e Abramovich (1989). Além de livros com vários colaboradores, como Khéde (1986), entre outros(as) autores(as). Nas obras do segundo grupo, voltadas para o âmbito escolar, pode-se citar: A literatura infantil na escola, de Zilberman (1982); Literatura infantil \& juvenil: vivências de leitura e expressão criadora, de Resende (1992); Literatura e alfabetização, de Saraiva (2001) e Como usar literatura infantil na sala de aula, de Faria (2004). Há ainda livros de caráter teórico, que tanto refletem sobre o conceito de literatura infantil quanto discutem valores estéticos de obras e outras questões, como Literatura infantojuvenil: leituras críticas, de Turch e Silva (2002) e Alice que não foi ao país das maravilhas, de Amarilha (2006), e todo um conjunto de obras com vários colaboradores, como a importante coleção Literatura e Educação, coordenada por profissionais do Centro de Alfabetização, Leitura e Escrita da Universidade Federal de Minas Gerais (Ceale-UFMG), que está no volume nove. Neste tópico, um destaque deve ser feito para Problemas da literatura infantil, de Cecília Meireles (1979), cuja atualidade das questões pode ainda ser observada.

Muitas são, portanto, as contribuições desses livros, como a ênfase em uma nova concepção de infância e suas consequências na criação de obras literárias, voltadas para esse segmento. Tendo em vista que a infância é um período elástico, sempre houve uma tendência de associar a literatura infantil a crianças alfabetizadas ou em processo de alfabetização - de leitura da palavra escrita.

O que se denomina Educação Infantil, período compreendido de 0 a 5 anos de idade, até o final do século $X X$, quase sempre ficou fora das pesquisas e dos relatos de vivência de/com leitores. Daí a importância de duas obras totalmente direcionadas para a reflexão sobre o lugar da literatura na Educação Infantil. Trata-se dos livros Literatura e Educação Infantil: livros, imagens e práticas de leitura (volume 1) e Literatura e Educação Infantil: para ler, contar e encantar (volume 2), organizados por Renata Junqueira de Souza e Cyntia Graziela G. Simões Girotto (2016), que 


\section{Penista Leteas Paras \\ ISSN: 2317-2347 - v. 9, n. 4 (2020) \\ Todo o conteúdo da RLR está licenciado sob Creative Commons Atribuição 4.0 Internacional}

problematizam e discutem as várias possibilidades de abordagem da literatura nos anos iniciais da criança na escola, a partir de perspectivas interativas, sempre articulando teoria e prática.

Fruto de um projeto de pesquisa capitaneado pelo Centro de Estudos em Leitura e Literatura Infantil e Juvenil (CELLIJ), da Universidade Estadual Paulista (Unesp) de Presidente Prudente/SP, e do diálogo entre pesquisadores de diferentes instituições de ensino superior, cada volume traz suas especificidades, embora os livros estabeleçam entre si muitos diálogos. Podese dizer que, na obra organizada por Girotto e Souza (2016), propõe-se a defesa de uma infância leitora e aponta os caminhos para sua realização. As duas obras reúnem dezoito textos, nove em cada volume, e, conforme explicitam as organizadoras, Girotto e Souza $(2016$, p. 7) "formaliza e documenta resultados e implicações teórico-metodológicos dessa investigação na/para/com a infância".

Voltada para a educação infantil, a obra pode contribuir num processo de formação inicial e continuada de professores, como as próprias organizadoras anunciam na apresentação do livro. No entanto, sua leitura é uma contribuição teórico-metodológica para qualquer leitor interessado na formação de leitores de literatura.

\section{Volume 1}

O volume 1 percorre, em nove capítulos, os caminhos iniciais para uma experiência literária. As autoras resguardam a ideia de uma prática docente que desmistifique a organização didático-literária adaptada do Ensino Fundamental para a Educação Infantil.

Apesar de uma apresentação em volumes independentes, os temas explorados no primeiro volume, muitas vezes, são retomados na segunda etapa do trabalho e conseguem dialogar. 0 ensaio que abre o volume 1, assinado pelas organizadoras e denominado "Práticas de leitura na infância: desatando os nós da formação de ouvintes e leitores", traz, entre outros aspectos, uma reflexão sobre a importância de revisitar a "literatura infantil para reintegrá-la de forma dinâmica e criativa no cotidiano escolar" (GIROTTO; SOUZA, 2016, p. 12).

As autoras realizam inúmeras perguntas, às quais procuram responder de modo bastante satisfatório, mas, independentemente das respostas, esses questionamentos devem nos inquietar cotidianamente em nosso trabalho com o texto literário. Destaquemos algumas: "Ler em voz alta é uma prática de leitura? Narrar história por meio da contação forma o leitor? Ter acesso aos livros 


\section{Peuista Letras Parar \\ ISSN: 2317-2347 - v. 9, n. 4 (2020) \\ Todo o conteúdo da RLR está licenciado sob Creative Commons Atribuição 4.0 Internacional}

na condição de crianças pequenininhas leva ao ato genuíno de ler? Quais armadilhas pedagógicas podem estar presentes nas diversas práticas escolares notadamente chamadas de leitura? Quais os nós aí presentes a serem desatados?" (GIROTTO; SOUZA, 2016, p. 14). Toda abordagem é permeada pelo diálogo com "a filosofia da linguagem, a teoria da aprendizagem com base na perspectiva histórico-cultural, os estudos psicolinguísticos e literários" (GIROTTO; SOUZA, 2016, p. 12), teorias que embasam boa parte dos demais capítulos. Mas essas perspectivas teóricas estão em consonância com a "experiência prático-reflexiva de alguns anos (como contadoras de histórias, mediadoras de leitura, no lugar de mães, tias, amigas; e também como docentes na condição de professoras formadoras, pesquisadoras, com projetos de extensão e de pesquisa atrelados à educação literária)" (GIROTTO; SOUZA, 2016, p. 12). Portanto, ajuntam-se aqui a formação teórica e o saber nascido da prática de formação de leitores, contribuindo, sobremaneira, para a formação de professores-leitores.

Os pressupostos teóricos e práticos podem contribuir com o trabalho do profissional envolvido com a formação de leitores dos anos iniciais, mas não apenas professores, como também pais, familiares em geral, bibliotecárias, pois, para as autoras: "A atitude dos adultos, como mediadores de narração, no ambiente em que a criança vive, assim, é fator de influência sobre a imaginação" (GIROTTO; SOUZA, 2016, p. 29). E mais, o "papel dos adultos como elo entre a criança e o ambiente físico, além do clima social criado pela família ou pelas instituições educativas, fazem diferença na qualidade da vida imaginativa" (GIROTTO; SOUZA, 2016, p. 29).

O segundo texto "Leitura e literatura na infância", de Suely Amaral Mello, tem também caráter ensaístico. A autora inicialmente discute pesquisas voltadas para a leitura no Brasil, para, em seguida, trazer questões relativas à "formação do desejo de ler". Apoiada, sobretudo, numa perspectiva vigostskyana, destaca que "a criança aprende socialmente, com o outro, o prazer de ler; cria para si a necessidade da leitura como vivência do próprio ato de ler com o outro" (MELLO, 2016, p. 46). Ao refletir sobre a educação literária na infância, lembra que ela "prepara - no melhor sentido - 0 adulto leitor, que lê não apenas porque sabe que é bom, mas porque é capaz, ao ler, de compreender melhor a si mesmo, aos outros, ao mundo em que vivemos e de se lançar em muitos outros" (MELLO, 2016, p. 54). Defende ainda que, "ao se apropriar dos livros em sua função social, isto é, ao reproduzir com os livros a função adequada para a qual foram criados - ao imitar o gesto leitor inicialmente e ao tomar o livro para ler posteriormente -, as novas gerações reproduzem para si as capacidades humanas criadas ao longo da história" (MELLO, 2016, p. 46). 


\section{Peuista Letras Paras}

ISSN: 2317-2347 - v. 9, n. 4 (2020)

Todo o conteúdo da RLR está licenciado sob Creative Commons Atribuição 4.0 Internacional

Ana Laura R. da Silva e Aletéia E. A. Chevbotar, no terceiro capítulo, "Os bebês e os livros: a comunicação afetiva", focalizam os bebês e suas relações com a literatura. Nessa parte do livro, são dadas direções mais específicas, indicando práticas para a exploração do conteúdo com esse público. Pensar o livro como objeto cultural é defendido durante toda a discussão, bem como são apresentadas as funções do adulto-mediador, que, a partir de recursos variados, deve aproximar a criança desse objeto cultural. As autoras retomam a tese de que o homem não nasce humano, defendida pela teoria histórico-cultural. Portanto, as qualidades humanas "são externas a ela [criança] e serão formadas pela atividade que ela realiza em seu convívio com as pessoas e com a cultura" (SILVA; CHEVBOTAR, 2016, p. 58). A partir do contato com a língua materna, da exploração tátil, dentre outros elementos de ativação dos sentidos, ocorrem atribuições de significados aos livros-objetos.

No quarto capítulo, "Os objetos e os livros: a criança de 1 a 3 anos", são abordadas as atividades com o livro literário entre crianças de 1 e 3 anos de idade. Assinado por Aline E. M. Ribeiro, Elieuza A. de Lima e Greice F. da Silva, o texto apresenta sugestões de atividades específicas para a criança, reiterando que "em cada etapa da formação humana, existe uma atividade mais propícia que conduz às mudanças mais importantes do ponto de vista psíquico e emocional" (RIBEIRO; LIMA; SILVA, 2016, p. 87). Lembram ainda que, "à medida que a criança se familiariza com o mundo da literatura, gradativamente nasce nela o desejo de se apropriar da competência que lhe ajudará a extrair, sem qualquer ajuda, novas histórias dos livros" (RIBEIRO; LIMA; SILVA, 2016, p. 97).

A leitura literária como prática social, com ênfase no contato do leitor com a linguagem escrita, é a base do quinto capítulo, escrito por Amanda Valiengo e Silvana P. de Souza, denominado "O mundo do faz de conta e os livros: a criança de 3 a 6 anos". As pesquisadoras apresentam uma proposta que tem link direto com o que vai ser tratado no capítulo 1 do volume 2. Valiengo e Souza (2016, p. 105) descrevem "as ações que podem mediar o acesso ao texto escrito e a função docente no processo de apropriação do livro de literatura, como objeto cultural". Enfatizam a perspectiva da literatura acessível, mesmo antes da apropriação, pela criança, da cultura escrita. Valiengo e Souza apresentam as atividades principais para cada faixa etária, associando as alternativas que a literatura oferece em paralelo. Entre as atividades, enfatizam a contação diária ou semanal, ofertada por meio de mediações planejadas. Destacam, nessa prática, a noção temporal, as predições, as conexões, o contato com materiais diversificados, a ampliação de vocabulárioe a exploração da atenção e da memória. 


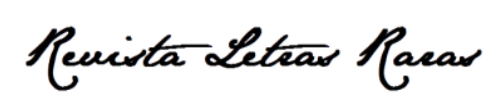

ISSN: 2317-2347 - v. 9, n. 4 (2020)

Todo o conteúdo da RLR está licenciado sob Creative Commons Atribuição 4.0 Internacional

Os capítulos subsequentes proporcionam um passeio analítico pelo livro infantil. Em "O acervo PNBE: por dentro e por fora dos livros", Berta Lúcia T. Feba e Thiago Alves Valente dão foco para o que denominam como as dimensões do livro infantil: a material, a verbal e a não verbal das obras. As reflexões fornecem aos professores parâmetros para a escolha do repertório de leitura em sala de aula. Os autores trabalham com o conceito de livro-brinquedo e discutem as possibilidades experienciais dos objetos culturais. Destaca-se, neste texto, a discussão sobre especificidades na abordagem do poema. Para Feba e Valente (2016, p. 142-143), "o trabalho com a poesia demanda não só atenção em relação a elementos da estrutura - rimas, métrica, aliterações, assonâncias - mas, sobretudo, a relação desses elementos com os sentidos expressos ou indiciados no texto".

Ainda no contexto de produção do livro infantil, o sétimo capítulo, cujo título é "O texto, quando se transforma em livro", de Norma Sandra de A. Ferreira e Lilian Lopes M. da Silva, apresenta uma reflexão sobre a relação sociocultural que existe entre leitor e livro, como objeto cultural. Para as autoras, "o livro é um objeto específico da cultura letrada, carregado de sentidos possíveis de serem compartilhados pela comunidade que produz e usa esse objeto, que com ele opera e coloca em circulação" (FERREIRA; SILVA, 2016, p. 149). 0 texto traz uma análise do livro Dez Sacizinhos, de Tatiana Belinky, destacando as "expectativas que os leitores contemporâneos podem construir em torno dele", "os significados e sentidos que ela pode produzir nos leitores", as "representações dos leitores pressupostos para ele" e, por fim, "as práticas de leitura previstas em circulação nos nosso meio cultural" (FERREIRA; SILVA, 2016, p. 153-154).

Fabiane V. Burlamaque e Tania M. K. Rösing assinam o oitavo capítulo do primeiro volume, denominado "A releitura de contos de fadas: processo (trans)formador na primeira infância". As autoras lembram que "um repertório de histórias que circulam entre as pessoas do povo" foi sendo transmitido "de geração para geração, repetindo-se com pequenas variações nos mais pequenos pontos do continente europeu" e que foi "a adaptação desse acervo popular, de tradição marcadamente oral, que chegou até os nosso dias" (BURLAMAQUE; ROSING, 2016, p. 163). O capítulo mostra "as diferentes possibilidades de se trabalhar com a história Chapeuzinho Vermelho, recriada por autores em diferentes épocas e contextos" (BURLAMAQUE; ROSING, 2016 , p. 173). Ao final, as autoras apresentam várias propostas de abordagem como: "modelagem: imaginando as personagens", "teatro de sombra: representando a história", "brincando eu conto e canto: inventando ações", "quadrinhos de histórias: recriando textos" e "minha tv notícia: anunciando histórias". 


\section{Penista Letras Paras}

ISSN: 2317-2347 - v. 9, n. 4 (2020)

Todo o conteúdo da RLR está licenciado sob Creative Commons Atribuição 4.0 Internacional

No nono capítulo, "O não-verbal no livro literário para criança”, Ana Paiva e Flávia Ramos percorrem a evolução histórica que demarca o livro voltado para criança, "com obviedades" e limitado em seus conteúdos, até chegar na contemporaneidade. Destacam que "alguns livros infantis contemporâneos definem-se pelo mix: livro + objeto + ação, ou seja, por propiciar à criança uma ação convidativa para exploração tátil, apreciação, leitura e interação direta" (PAIVA; RAMOS, 2016, p. 195), demandando dos profissionais educacionais um olhar mais aguçado e a compreensão mais desafiadora das demandas específicas da literatura para crianças. No decorrer do capítulo, são comentados vários livros, mostrando que as obras voltadas para o público infantil "investem na produção de imagens e suplementos lúdicos como tendência e isso não tende a ser impositivo, mas, sim, uma observação de demanda e expectativa do público" (PAIVA; RAMOS, 2016, p. 197).

\section{Volume 2}

O capítulo inicial do volume 2, de Elié Bajard, "Por um deslocamento do foco da alfabetização", inicialmente retoma algumas de suas reflexões já postas em livros. Para o autor, "se cada texto gráfico corresponde a um texto sonoro e, se este último pode ser compreendido pelo analfabeto, o foco da alfabetização não se localiza entre a fala e a escrita, mas entre o texto sonoro constituído por signos auditivos e o texto gráfico, composto por signos verbais" (BAJARD, 2016, p. 17-18). Basicamente o capítulo se dá a partir dessa percepção. Traz, ainda, no bojo da discussão, conceitos bastante presentes na prática de pesquisadores, como "reconto", "proferição", "espaço em branco", bem como uma discussão voltada para a "língua moderna". Apresenta também importante e polêmica discussão a respeito da autonomia da escrita, que não pode ser compreendida apenas como duplicação da "língua oral". Para ele, "a autonomia da escrita, garantida por seus signos gráficos, faz nascer um idioma abrangente, constituído de matéria gráfica e de matéria sonora, oferecendo à escrita a capacidade de reger a fala" (BAJARD, 2016, p. 26).

Neste volume, a discussão sobre "leitura em voz alta" é tema de vários capítulos, como no segundo, "A leitura em voz alta na Educação Infantil: o que e como ler"; no terceiro, "Onde ler em voz alta - preparando o ambiente mediador" de forma mais direta; mas também nos seguintes, que se voltam para a contação de histórias. 


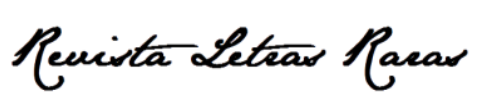

ISSN: 2317-2347 - v. 9, n. 4 (2020)

Todo o conteúdo da RLR está licenciado sob Creative Commons Atribuição 4.0 Internacional

O título do segundo capítulo, "A leitura em voz alta na Educação Infantil: o que e como ler", assinado por Maria A. Dalvi, Marta C. de Quadros e Kenia A. A. M. Silva, já sugere um estudo baseado na prática, fornecendo recursos sobre o que escolher e como ler na ocasião da leitura em voz alta na Educação Infantil. A apresentação da literatura infantil visando à construção de um cidadão autônomo, crítico e também ao seu desenvolvimento físico, cognitivo e sociológico demanda um trabalho direcionado antes, durante e depois da leitura. A relação entre leitor e livro, a recepção da leitura e o envolvimento intelectual, corporal, sensorial e emotivo entre ambos são destacados pelas autoras. Nesse sentido, a função do mediador torna-se fundamental, desde "[...] que tenha clareza de que há aspectos a serem ensinados e aprendidos que atravessam dimensões cognitivas, psicológicas e sociológicas imbricadas na leitura literária" (DALVI; SILVA, 2016, p. 37).

Uma continuidade na preparação do professor para a vivenciada leitura literária está explícita no capítulo 3, "Onde ler em voz alta - preparando o ambiente mediador", de Cyntia M. F. Ariosi, Gislene A. da S. Barbosa e Irando Alves M. Neto, em que se aborda a preparação de um ambiente mediador, diferenciando espaço e ambiente. Os autores apresentam a experiência de Regio Emília, proposta idealizada pelo italiano Loris Malaguzzi, para confirmar a relevância de dimensões e conceitos que precisam ser discutidos sobre a ambientação do espaço para a leitura literária. É de suma importância que o mediador tenha em mente, antes de tudo, seus objetivos para assim planejar a organização desse espaço. Visando à organização do espaço físico, retomam as quatro dimensões apontadas por Forneiro (1998): "1. Dimensão física, 2. Dimensão funcional, 3. Dimensão temporal e 4. Dimensão relacional" (ARIOSI; BARBOSA; NETO, 2016, p. 73). A partir daí, após explicitar cada dimensão, retomam o livro Dia de chuva, de Ana Maria Machado e exemplificam uma abordagem nessa perspectiva.

Tendo em vista a relevância da construção de uma prática de leitura planejada e adequada ao público leitor, o mediador assume uma posição também de leitor. É o que será também discutido no capítulo 4, "Ler na Educação Infantil: mediação, leitura e aprendizado", de Vania K. B. Vagula e Angela Balça, que dá continuidade às discussões sobre mediação, literatura e aprendizado. Ressaltam como essas vivências podem ser relevantes quando o professor é munido de teoria e orientações didáticas, como também reiteram a figura do professor como primeiro mediador, a partir do momento de inserção da criança na escola. Destacam a importância de 0 professor ser um leitor para se inteirar com os títulos, não impor leituras aos alunos e ser um bom comunicador. Nesse processo, defendem ser preciso ter conhecimento prévio sobre o texto, usar 


\section{Penista Leteas Pacar \\ ISSN: 2317-2347 - v. 9, n. 4 (2020) \\ Todo o conteúdo da RLR está licenciado sob Creative Commons Atribuição 4.0 Internacional}

recursos sonoros, propor e mediar a localização de elementos para o aluno e fazer pausas durante a leitura.

Os capítulos 5 e 6 apresentam uma perspectiva comum: a da literatura com base na afetividade. Em "A narração de histórias na infância: técnicas e interação", Celso Sisto e Juliane Motoyama ressaltam como contar histórias pode ser visto como um ato de criação de uma atmosfera em que o ouvinte olha, sente e recria a sua própria história. Os autores apontam como o contador de histórias afeta o outro e apresentam técnicas e recursos para esse fim. Apesar de serem práticas pessoais e intransferíveis, as técnicas não excluem a capacidade de improvisação e isso é que possibilita o processo de humanização na hora de contar. Os autores apresentam várias práticas e recursos que podem ser usados pelo mediador, bem como destacam a importância da preparação da atividade de contar/narrar. Afirmam, por fim, que, "independente da forma como se opta por contar uma história, em primeira ou terceira pessoa, com o público longe ou perto, com o público dentro ou fora da história, o importante é que o contador se prepare previamente e sinta que o texto lhe permite fazer uso desses e outros procedimentos [...]" (SISTO; MONTOYAMA, 2016, p. 127).

Já em "O mel do acalanto e o trovão do espanto: a voz no contar histórias", de Gilka Girardello e Valéria S. da Silva, o momento da contação é tido como um aconchego nutritivo "em que 0 afeto não se separa da dimensão física do falar, em que a história vem embalada por uma voz que acaricia [...]" (GIRARDELO; SILVA, 2016, p. 142). Ressaltam, neste capítulo, como as variações no tom de voz são determinantes para o acompanhamento e a compreensão das etapas da cena e narrativa como um todo, uma vez que, conforme Grainger (1997, p. 155), "os efeitos vocais agem como recurso e apoio à memória e de encorajamento à participação das crianças na brincadeira coletiva". Para as autoras, "O texto literário e as práticas de leitura literária na Educação Infantil possibilitam a apropriação de um patrimônio cultural produzido pela humanidade ao longo de milênios [...]" (GIRARDELO; SILVA, 2016, p. 156). Também apontam vários recursos, como "formas animadas", "fantoche e deboche", "contos desenhados", "contos que as caixas contam", "televisão de mentirinha", "flanelógrafo" e "avental".

Os capítulos que encerram o volume 2 exploram recursos, documentos norteadores e a retomada da literatura como atuante nesse processo de humanização. No capítulo intitulado "Os recursos para contar histórias: das tramas que o entretecem", Eliane Debus e Silvana F. de S. da Balsan fazem uma abordagem inicial sobre a relação entre 0 ato de narrar histórias e o ser humano e como essa prática pode ser considerada nata. No caso do espaço escolar, o texto aborda as 


\section{Peuista Letras Parar \\ ISSN: 2317-2347 - v. 9, n. 4 (2020) \\ Todo o conteúdo da RLR está licenciado sob Creative Commons Atribuição 4.0 Internacional}

Diretrizes Curriculares Nacionais da Educação Infantil e da Educação Básica para contextualizar a necessidade de um olhar específico diante das práticas. Para promover o prazer e ampliar a visão de mundo, "faz-se necessário criar momentos ou proporcionar situações para que as crianças construam ou ampliem suas experiências com a leitura literária, desenvolvendo assim 0 apreço pela literatura" (DEBUS; BALSAN, 2016, p. 160). As autoras, apesar das múltiplas propostas, ressaltam que, mesmo diante das estratégias, o professor não pode se desvincular do foco principal da história: a narrativa. Os recursos, portanto, são possibilidades para a apresentação principal.

No capítulo 8, "A construção de histórias: o entorno em questão", Elieuza A. de Lima, Cristiane R. X. Fonseca-Janes e Rosane M. de Castro retomam a teoria histórico-cultural como alicerce de suas reflexões. Consideram o "fenômeno linguístico [...] antes de tudo, histórico, dinâmico e uma prática social" e, como consequência, "as histórias contadas às crianças pequenas em cada situação, em cada momento, são uma prática discursiva diferente. Não existiria assim uma única regra a seguir, mas uma dinamicidade única de cada grupo em que as histórias são contadas" (LIMA; FONSECA-JANES; CASTRO, 2016, p. 179). Segundo as autoras, ao indagar sobre a "possibilidade de influência que as narrativas podem exercer sobre as capacidades humanas", é necessário também indagar "sobre seu entorno, em tudo aquilo que envolve essa atividade desde o meio, o ambiente, as relações estabelecidas entre ouvinte e contador(a), as mediações e as capacidades humanas a serem desenvolvidas" (LIMA; FONSECA-JANES; CASTRO, 2016, p. 182). A reflexão sobre a interação entre crianças, contador(a) e espaço é da maior importância, tendo em vista um trabalho de formação de leitores dinâmico, jamais constituído numa prática mecânica e repetitiva de contação.

A formação do professor é o assunto que destacamos no capítulo que encerra a obra. Assinado pelas organizadoras Renata J. de Souza, Cyntia G. G. S. Girotto e por Irando Alves M. Neto, o capítulo "Caminhos para o ensino da leitura literária na Educação Infantil" reflete e aponta possibilidades concretas de formação do professor que tem o desejo de proporcionar aos alunos experiências com a amplitude que a literatura oferece ao público infantil. Alguns dos tópicos discutidos, como "estabelecimento de objetivos claros", "modelo de leitura fluente", discussão do texto", "leitura independente", oferecem uma orientação firme no trabalho de formação dos leitores. Mas, para que essa prática se efetive, "uma formação adequada permitiria que o docente, além de saber aplicar eficientemente as propostas por nós apresentadas, pensasse, aliando as teorias as suas práticas, em novas possibilidades para o ensino da literatura infantil" (GIROTTO; SOUZA; 


\section{Penista Leteas Pacar \\ ISSN: 2317-2347 - v. 9, n. 4 (2020) \\ Todo o conteúdo da RLR está licenciado sob Creative Commons Atribuição 4.0 Internacional}

NETO, 2016, p. 214). Destacamos, aqui, a ênfase na formação inicial, básica e contínua, que mantenha a atualização no olhar sobre a Educação Infantil e a literatura infantil, valorizando ambas as instituições e aceitando-as em suas especificidades.

\section{Por fim}

Por tudo que se afirmou sobre os capítulos que compõem a obra, estamos diante de uma das mais importantes colaborações para a reflexão e a prática da leitura literária na Educação Infantil. Queremos destacar, ainda, que muitas das questões e sugestões colocadas ao longo da obra alcançam também possíveis práticas nos anos iniciais do Ensino Fundamental. Portanto, tem um alcance bastante significativo para a formação de leitores de literatura, não se restringido apenas ao professor que atua na Educação Infantil.

No prefácio do livro, "As cem linguagens da criança", Edwards, Gandini e Forman (2016, p. 15) afirmam: "Saudamos o método da descoberta, mas não temos confiança para permitir [que] as crianças sigam suas próprias intuições e palpites". Para propor experiências literárias significativas, é necessário não temer o retorno das crianças e dar autonomia para que elas determinem qual informação é relevante naquele momento. A obra de Girotto e Souza torna essa construção mais clara e até óbvia para professores já atuantes e ainda em formação, fornecendo mais segurança para uma prática autônoma e intuitiva tanto dos mediadores quanto das crianças.

\section{Referências}

ABRAMOVICH, Fanny. Literatura infantil gostosuras e bobices. São Paulo: Scipione, 1989.

AMARILHA, Marly. Alice que não foi ao país das maravilhas: A leitura crítica na sala de aula. Petrópolis: Vozes, 2006.

ARROYO, Leonardo. Literatura infantil brasileira: ensaio de preliminares para a sua história e suas fontes. São Paulo: Melhoramentos, 1963.

EDWARDS, Carolyn P.;. GANDINI, Leila; FORMAN, George. As cem linguagens da criança: a abordagem de Reggio Emilia. Porto Alegre: Penso, 2016.KHÉDE, Sônia Salomão (org.). Literatura infanto-juvenil: um gênero polêmico. Porto Alegre: Editora Mercado Aberto, 1986.

LAJOLO, Marisa; ZILBERMAN, Regina. Literatura infantil brasileira: história \& histórias. 2. ed. São Paulo: Ática, 1985. 


\section{Peuista Letras Paras}

ISSN: 2317-2347 - v. 9, n. 4 (2020)

Todo o conteúdo da RLR está licenciado sob Creative Commons Atribuição 4.0 Internacional

MEIRELES, Cecília. Problemas de literatura infantil. 3. ed. São Paulo: Summus; Brasília: INL, 1979.

RESENDE, Vânia Maria. Literatura infantil \& juvenil: vivências de leitura e expressão criadora. São Paulo: Saraiva, 1992.

SARAIVA, Juracy Assmann (org.). Literatura e alfabetização: do plano do choro ao plano da ação. Porto Alegre: Artmed, 2001.

SILVA, Vera M. Tietzmann; TURCHI, Maria Zaíra. Literatura infanto-juvenil: leituras críticas. Goiânia: Editora da UFG, 2002. 